\title{
Solubility-pH profiles of a free base and its salt: sibutramine as a case study ${ }^{\ddagger}$
}

\author{
Diego Lucero-Borja ${ }^{1}$, Òscar Castilla ${ }^{1}$, Rafael Barbas ${ }^{2}$, Xavier Subirats ${ }^{1}$, Clara Ràfols ${ }^{1, *}$ \\ ${ }^{1}$ Institute of Biomedicine (IBUB) and Department of Chemical Engineering and Analytical Chemistry, Universitat de \\ Barcelona - Martí i Franquès, 1-11, 08028 Barcelona, Spain. \\ ${ }^{2}$ Polymorphism and Calorimetry Unit, Scientific and Technological Centers, Universitat de Barcelona - Travessera de \\ Les Corts, 131-159, 08028 Barcelona, Spain.
}

*Corresponding Author: E-mail: crafols@ub.edu; Tel.: +34-934-034-874; Fax: +34-934-021-233

Received: September 29, 2017; Revised: November 26, 2017; Published: December 24, 2017

\begin{abstract}
In the present study the solubility-pH profiles of sibutramine free base and its hydrochloride salt were determined in the $\mathrm{pH}$ range between 2.0 and 9.5 by means of the recommended shake-flask method, and the solids collected were dried and studied by $X$-ray diffraction in order to elucidate their free base or salt structure. Above $\mathrm{pH}_{\max }$ (or Gibbs $p K_{a}$ ) the solid collected was always identified as free base, whatever the sibutramine species (free base or hydrochloride salt) initially solved. However, in the $\mathrm{pH}$ range below $\mathrm{pH}_{\max }$ different solids were isolated depending on the buffers employed.
\end{abstract}

\section{Keywords}

Buffer; free base; pH profile; potentiometry; salt; shake-flask, solubility.

\section{Introduction}

In drug formulation it is well known that salts from basic compounds are generally more stable and soluble than their corresponding free bases and, therefore, the salt form is preferred for use as active ingredient in a pharmaceutical form. Thus, the study of the solubility of a compound as a function of $\mathrm{pH}$, the solubility-pH profile, provides very useful information about the physicochemical properties of a compound and its rate of success as a drug candidate. In the case of weakly basic active pharmaceutical ingredients, at higher $\mathrm{pH}$ values $\left(\mathrm{pH}>>\mathrm{pK}_{\mathrm{a}}\right)$ the solubility is constant and independent of $\mathrm{pH}$, and the solid phase in equilibrium with the saturated solution is the free base. In contrast, at acidic $\mathrm{pH}$ values $\left(\mathrm{pH} \ll<K_{\mathrm{a}}\right)$ the solid in equilibrium with the cationic base is a salt, whose composition depends on the anionic components of buffering species. The particular salt formed is relevant because of its influence on the maximum achievable concentration of the saturated solution. Between this acidic and basic $\mathrm{pH}$ regions there is a particular $\mathrm{pH}$ value, known as $\mathrm{pH}_{\max }$ or $\mathrm{p} K_{\mathrm{a}} \mathrm{Gibbs}$, for which the solution is saturated with both, the free and the cationic species, and the solid in equilibrium contains also free base and salt [1].

The crystalline racemic compound sibutramine hydrochloride monohydrate was used as the active pharmaceutical ingredient of medicines for the management of obesity from 1999 to 2010. Its withdrawal 
from European and US markets was due to cardiovascular side effects. However, the physicochemical properties of sibutramine (molecular weight, acidity, solubility, lipophilicity...) make it a very interesting model for the solubility study of basic compounds.

\section{Experimental}

The solubility-pH profiles of sibutramine (free base) and its hydrochloride salt have been determined at $25{ }^{\circ} \mathrm{C}$ in the $\mathrm{pH}$ range between 2.0 and 9.5 by means of the shake-flask method using the recommended protocol [2]. Briefly, a mass spectrometry-friendly minimalist universal buffer (MS-MUB) consisting of 25 $\mathrm{mM}$ acetic acid, $25 \mathrm{mM}$ ethylenediamine, and $75 \mathrm{mM}$ trifluoroacetic acid (TFA) was used, incubation was carried out for $48 \mathrm{~h}$ ( $24 \mathrm{~h}$ stirring and $24 \mathrm{~h}$ sedimentation), $\mathrm{pH}$ was measured after $4 \mathrm{~h}$ of stirring and readjusted if necessary with sodium hydroxide or hydrochloric acid, and finally the $\mathrm{pH}$ was measured again before the phase separation by centrifugation. Sibutramine concentration was determined by HPLC with UV detection and the solid was vacuum filtered and dried for $24 \mathrm{~h}$ in order to elucidate their free base or salt structure by powder X-ray diffraction (PXRD).

With the aim of evaluating the effect of the MS-MUB components on the precipitated solid, simple solutions prepared from acetic acid, trifluoroacetic acid, and hydrochloric acid were used. Finally, the Henderson-Hasselbalch $(\mathrm{HH})$ profile was constructed from the spectrophotometrically determined $\mathrm{p} K_{\mathrm{a}}[3]$ and the intrinsic solubility measured by the CheqSol method [4].

\section{Results and Discussion}

pH change during stirring step in the shake-flak procedure

A universal buffer was selected in the present work in order to keep nearly constant the ionic strength of the buffering solution across the studied $\mathrm{pH}$ range, but intentionally avoiding phosphate ions because they are well known to interact with positively charged bases. Besides these features, it is always interesting to count on a MS-friendly buffer, since liquid chromatography coupled to MS is a powerful technique for the measurement of low concentrations of poorly soluble substances. Therefore, MS-MUB was used, providing in the whole $\mathrm{pH}$ working range an ionic strength of $96 \mathrm{mM}$ but being thought to be minimally intrusive in relation to anionic buffering species.

The $\mathrm{pH}$ measurements after 4 hours of stirring revealed significant variations (above $1 \mathrm{pH}$ unit) in relation to the initial $\mathrm{pH}$ of the buffer before the addition of the solid, which depends on the nature of starting solid. In fact, there is a remarkable increase in the $\mathrm{pH}$ value of acidic solutions $(\mathrm{pH}<4)$ when the free base is used as starting species, and the reverse trend is observed for the hydrochloride salt at basic $\mathrm{pH}$ values. In the rest of cases, free base/basic $\mathrm{pH}$ and salt/acidic $\mathrm{pH}, \mathrm{pH}$ variations are not significant during the stirring step.

\section{Effect of buffer components on solubility-pH profile}

Figure 1 shows the solubility-pH profile of sibutramine according to the buffering species used in the shake-flask procedure, and Figure 2 relates the solubility with the solid species initially selected for the experiments (free base or hydrochloride salt) and the solid collected and dried after centrifugation. There is a good agreement between the shake-flask results and the $\mathrm{HH}$ profile in the $\mathrm{pH}$ range above $\mathrm{pH}_{\max }$, independently of the sibutramine form initially weighted and the buffering species employed, and in this $\mathrm{pH}$ region the solid collected was always identified by PXRD as the free base. In contrast, a salt was 


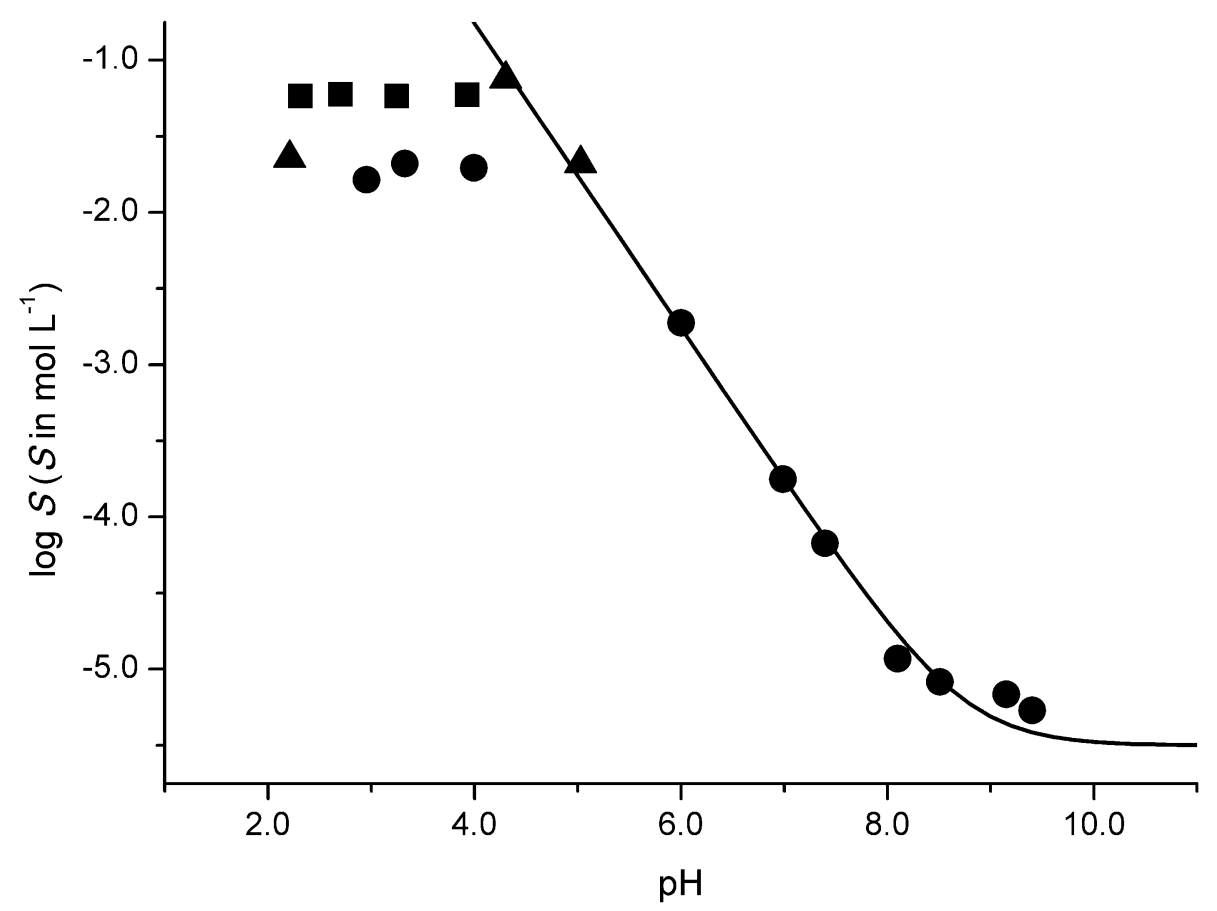

Figure 1. Solubility-pH profile of sibutramine according to the buffering species used in the shake-flask

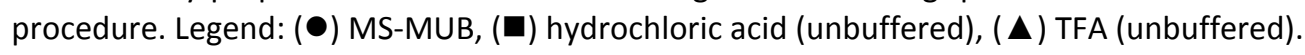

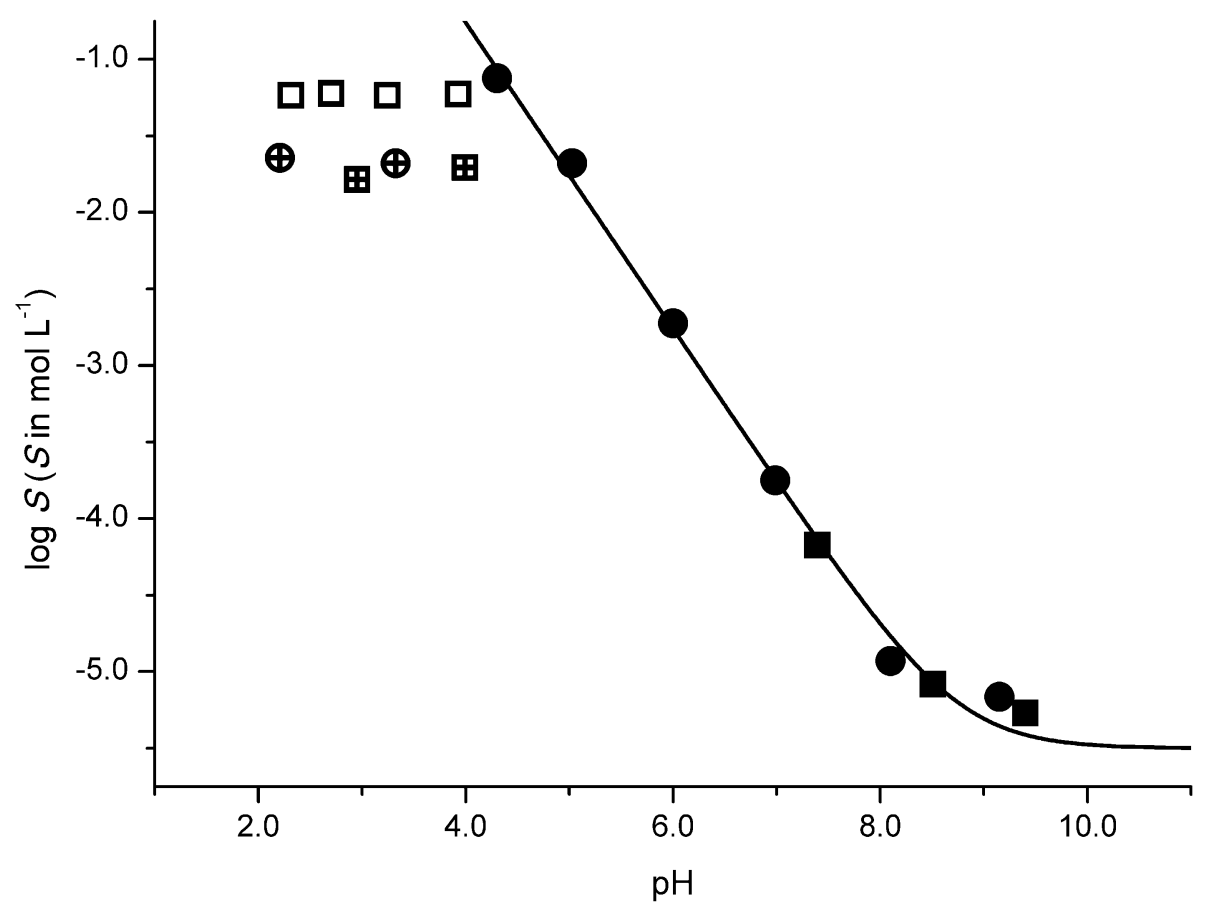

Figure 2. Solubility-pH profile of sibutramine according to the initial weighted solid form and the collected solid after shake-flask procedure identified by PXRD. Legend: circles and squares refer to initial species, free base or sibutramine $\cdot \mathrm{HCl}$, respectively; solid, empty, and crossed symbols indicate collected solids as free base, $\mathrm{HCl}$ salt, and TFA salt, respectively.

expected in the $\mathrm{pH}$ range below $\mathrm{pH}_{\max }$, but in fact two different solids were isolated depending on the buffers employed. When MS-MUB or its single component TFA were used the dried solid was identified as sibutramine-TFA salt, whereas when only hydrochloric acid was employed the corresponding solid was the hydrochloride salt. Interestingly, the solubility of the compound in equilibrium with the solid TFA is slightly lower than that of $\mathrm{HCl}$ salt. The TFA salt was formed independently of the starting sibutramine species, free base or hydrochloride salt. 


\section{Conclusions}

It is very convenient to periodically measure and readjust (if necessary) the $\mathrm{pH}$ of the saturated solution of drug, especially during the first hours of the stirring step. The sign and extent of the variation depends on the initial form of the compound (free base or salt) and the particular working $\mathrm{pH}$.

Single anionic components of universal buffers, for instance TFA in MS-MUB, may interact with positively charged basic drugs leading to unexpected salts in equilibrium with the saturated solution, affecting thus the solubility of the compound.

Acknowledgements: This work was supported by the Ministry of Economy and Competitiveness of Spain (project CTQ2014-56253-P).

\section{References}

[1] P.H. Stahl, C.G. Wermuth, eds., Handbook of Pharmaceutical Salts. Properties, Selection, and Use, Verlag Helvetica Chimica Acta, Zürich, Switzerland, 2002.

[2] A. Avdeef, E. Fuguet, A. Llinàs, C. Ràfols, E. Bosch, G. Völgyi, T. Verbić, E. Boldyreva, K. TakácsNovák, Equilibrium solubility measurement of ionizable drugs - consensus recommendations for improving data quality, ADMET DMPK 4 (2016) 117-178. doi:10.5599/admet.4.2.292.

[3] K.Y. Tam, K. Takács-Novák, Multi-wavelength spectrophotometric determination of acid dissociation constants: A validation study, Anal. Chim. Acta. 434 (2001) 157-167. doi:10.1016/S0003-2670(01)00810-8.

[4] M. Stuart, K. Box, Chasing equilibrium: Measuring the intrinsic solubility of weak acids and bases, Anal. Chem. 77 (2005) 983-990. doi:10.1021/ac048767n.

C2017 by the authors; licensee IAPC, Zagreb, Croatia. This article is an open-access article distributed under the terms and conditions of the Creative Commons Attribution license (http://creativecommons.org/licenses/by/3.0/) (cc) BY 